\title{
Die Diskreetheid van Materie
}

(Rede uitgespreek by die aanvaarding van die professoraat in Fisika aan die P.U. vir C.H.O., op 15 Februarie 1957, deur dr. P. H. Stoker).

\section{Inleiding:}

Onder die diskreetheid van materie verstaan ons dat materie nie 'n kontinue struktuur het nie, dus nie willekeurig en oneindig deelbaar is nie, maar opgebou is uit klein deeltjies, wat afsonderlik en apart kan bestaan.

Die diskreetheid van materie staan vandag na soveel eeue nog in die brandpunt van die belangstelling en ontwikkeling van die Natuurkunde. Vir die Griekse wysgeer Democritus en sy volgelinge was alle materie opgebou uit diskrete onveranderlike en ondeelbare deeltjie, wat atome genoem is. Hierdie atoomgedagte uit die vyfde eeu voor Christus het gespruit uit wysgerige beskouings wat ' $n$ verandering in enige stoflike voorwerp wou teruglei tot die beweging van onveranderlike oerdeeltjies. Eers teen die negentiende eeu na Christus het die atoomgedagte van die ou Griekse wysgere natuurwetenskaplike waarde begin verkry toe Dalton die atoomteorie ontwikkel het om 'n doeltreffende beskrywing en 'n aanneemlike verklaring vir eksperimentele gegewens te bied. Hierdie teorie het uitgegaan van atome as die onveranderlike en ondeelbare elementêre bestandele van alle stoflike voorwerpe. $\mathrm{Na}$ ontplooiing het die atoomteorie van Dalton die eksperimentele toetsing van die klassieke Natuurkunde op 'n oortuigende wyse deurstaan. Steeds het as voorveronderstelling gegeld die beginsel van behoud van massa, wat die onvernietigbaarheid van atome impliseer, en die beginsel van behoud van energie.

Met die ontdekking van die elektron teen die end van die negentiende eeu het die atoom tog deelbaar geblyk te wees. Aangesien materie uit atome opgebou is, volgens die teoretiese beskouings, behoort die elektrone uit die atome self te kom, en dus 'n bestanddeel van atome te wees.

Kort na die elektron is radioaktiwiteit ontdek, wat getoon het dat atome ook veranderlik is in hulle chemiese en fisiese eienskappe deurdat atome van die een element na 'n ander spontaan desintegreer. Daarmee het dan die vraag ontstaan wat dan die struktuur en samestelling van die atome is. Die atome is nie meer die elementêre en onveranderlike vestanddeel van ma- 
terie nie. Die beantwoording van hierdie vraag het meegebring dat gedurende die afgelope halwe eeu die natuurkundige idee en wysgerige beskouinge van materie in baie opsigte heeltemal gewysig moes word. Nie alleen is die beskouinge van materie gewysig nie; ook die onverbreekbare en presiesbepaalbare bewegingswette waaraan materiedeeltjies in die klassieke Fisika moes voldoen, moes prysgegee word.

Hierdie wysiging van die klassieke atoomteorie en van die presiesbepaalende bewegingswette is nie alleen in die hand gewerk deur die eksperimentele ontdekkings dat die atoom wel deelbaar en veranderlik is nie, maar is ook teweeggebring om sekere optiese en elektromagnetiese verskynsels te kan verklaar. Lig en elektromagnetiese strale is in navolging van Maxwell beskou as ' $n$ kontinue golfbeweging van elektriese en magnetiese velde. Hierdie opvatting van lig en elektromagnetiese strale kan egter nie die eksperimentele resultate verklaar wat verkry word as lig bv. op 'n stoflike voorwerp val nie. Die eksperimentele waarnemings toon aan dat die energie van die ligstrale nie op 'n kontinue wyse aan materie oorgedra word nie, maar in klein diskrete hoeveelhede. Hierdie resultate het Einstein in 1905 met sy foto-elektriese wet die eerste keer geformuleer. Hierdie foto-elektriese wet kan alleen afgelei word indien veronderstel word dat die energie van lig en elektromagnetiese strale gekwantiseerd d.i. diskreet is, ooreenkomstig die kwantisering van die energie van warmtestrale, wat Max Planck in 1900 moes aaneem om die empiriese wette van warmtestrale teoreties af te lei.

Deur die wysiging van die klassieke teorië en opvattinge kon vir die elektron plek in 'n atoomteorie gegee word. Aldus kon fisiese verskynsels deur prosesse waaraan die elektron deel het, verklaar word. Die elektron is as ' $n$ inherente bestanddeel van atome beskou. Dit het bv. dan ook die verklaring en teoretiese berekenings van die binding van atome tot molekule en in kristalstrukture moontlik gemaak.

\section{Die realiteit van die diskreetheid van materie:}

Dat ons fisiese verskynsels kan verklaar en met mekaar in verband kan bring deur die diskreetheid van materie aan te neem, is nog nie 'n bewys dat materie werklik diskreet is nie en nie net in ons denke, soos o.a. die positiwiste dit wil sien nie. Om die realiteit ven die diskreetheid van materie na te gaan, moet ons op die fisiese verskynsels let wat vir ons aantoon dat materie nie 'n kontinue struktuur het nie of wat dui op die bestaan van materiedeeltjies wat op 'n diskrete wyse van mekaar in hulle fisiese verskynsels verskil. 
Eerstens kan genoem word die diskontinue beweging soos deur Brown ontdek, van klein kolloïdale stofdeeltjies in 'n gas of vloeistof, wat duidelik met 'n mikroskoop waargeneem kan word. Die diskontinue beweging dui op 'n diskreetheid in die struktuur van die vloeistof of gas waarin die deeltjies in kolloïdale oplossing is.

Verder kan materiedeeltjies ook een vir een waargeneem word. 'n Snelbewegende deeltjie veroorsaak bv. 'n ligflitsie op 'n fluoreserende skerm wat met 'n mikroskoop maklik waargeneem kan word. Ook kan die bewegingsbane van individuele deeltjies in die wolkkamer van Wilson of in fotografiese emulsies afgeteken word. Verskillende tipes bane kan duidelik onderskei word en daaraan kan die tipe deeltjies uitgeken word. Dit is juis hierdie metodes van waarneming op individuele deeltjies en prosesse, waaraan hulle deel het of veroorsaak, wat gelei het tot die ontdekking van 'n reeks subatomêre deeltjies, in besonder die mesone. Vir elke tipe baan kon 'n massawaarde afgelei word. Die massawaardes van hierdie subatomêre deeltjies gee dan ook 'n aantal diskrete waardes. Hierdie gegewens bevestig op 'n direkte wyse die diskreetheid van materiedeeltjies.

Atome is nie alleen deelbaar nie. Hulle is ook veranderlik. Atome van die een chemiese element kan vandag met verskillende reaksies na atome van ' $n$ ander element getransformeer word. Die onveranderlikheid van die atome van die 92 chemies elemente uit die vorige eeu is vandag gereduseer tot die onveranderlikheid van twee elementêre deeltjies, nl. die elektron en die proton. Hierdie twee deeltjies word saam met die neutron beskou as die diskrete bestanddele van 'n atoom. Neutrone is nie onveranderlik nie. In die vrye toestand is neutrone radioaktief-onbestendig en ontbind tot ' $n$ proton en ' $n$ elektron. Alle ander bekende deeltjies soos die mesone, waarvan die massawaardes wissel tussen dié van die elektron en heliumatome, is almal radioaktief-onbestendig.

\section{Metode van Fisika :}

'n Natuurverskynsel wat in 'n eksperimentele ondersoek tot openbaring kom is iets wat werklik bestaan, onafhanklik van die waarnemer. Sekere natuurverskynsels het ons alreeds genoem om die realiteit van die diskreetheid van materie aan te dui. Die eksperimentele ondersoek gaan egter verder as die objektiewe waarneming en beskrywing van die verskynsel. Metings word ook uitgevoer om fisiese groothede in kwantitatiewe verhoudings uit te druk. Alle fisiese metings word uitgevoer in terme van vooraf-gedefinieerde en -gestandardiseerde mate soos eenhede van lengte, 
massa, elektriese lading en so meer. Die kwantitatiewe waardes wat by metings op 'n natuurverskynsel gevind word, kan in 'n fisies-wiskundige vergelyking saamgevat word.

Van die natuurverskynsel kom ons dus deur meting tot die fisies-wiskundige vergelyking. Om die natuurverskynsel te ontleed en die vergelyking 'n betekenis te gee, moet beide verklaar kan word. Hierdie verklaring word neergelê in 'n denkbeeld van die fisiese presesse, wat ons die fisiese wêreldbeeld sal noem. Hierdie fisiese wêreldbeeld skakel dan aan die een kant met die natuurverskynsels en aan die ander kant met die fisiese teorie, wat 'n afleiding volgens wiskundige reëls van die vergelykings waarmee fisiese wetmatighede weergegee word, moontlik maak.

Die fisiese teorie met sy wiskundige afleidings is die ruggraat van Fisika. $\mathrm{Na}$ die een kant word die fisiese teorie verbind deur metinge met die realiteit van die waargenome natuurverskynsels en na die ander kant deur interpretasie van fisiese simbole en vergelykings met die fisiese wêreldbeeld. 'n Logiese ontwikkeling van die teorie lei weer tot die formulering van nuwe vrae aan die natuur by wyse van 'n eksperimentele meting.

Wiskunde word in die Fisika gebruik en ontwikkel om te beantwoord aan die vereistes van die vak. Fisika mag egter nie verwiskundig word nie, want dit bring mee dat die vak teruggevoer word na die getal en ruimte van Wiskunde, dus sonder 'n fisiese inhoud. Waar Wiskunde handel oor getal en ruimte, hou die Natuurkunde hom besig met die hele stoflike natuur, in besonder met materie, sy eienskappe en stoflike prosesse. In materie en sy prosesse vind Fisika dinge soos energie, massa, elektrisiteit, en so meer, maar ook getal en ruimte. Die fisiese wetskring volg dan ook op die wetskringe van getal en ruimte van Wiskunde. Alhoewel Fisika en Wiskunde elkeen soewerein is in eie kring, is daar tog ook 'n noue samehang tussen hulle, wat ondersoek en eerbiedig moet word sonder dat die een na die ander herlei word. Wiskunde en Fisika kan dan ook weersyds bevrugtend op mekaar inwerk.

Die huidige mikrofisika gaan vandag in die eerste plek van die fisieswiskundige teorie uit en in 'n baie minder mate as voorheen van fisiese modelle. Wanneer ons vandag aan 'n atoom dink, het ons in ons gedagtes soms ' $n$ voorstelling daarvan, of anders mag ons 'n skets daarvan probeer maak, meestal afgelei uit 'n fisies-wiskundige vergelyking. Die besonderhede van die voorstelling is egter met groter noukeurigheid en meer bruikbaar in die vergelyking vervat as wat 'n model ooit kan gee. Die ruimtelike afmetings van 'n atoom of deeltjie kan nie direk waargeneem en gemeet 
word nie. Die ruimtelike vorme en gedaantes word afgelei uit die wis kundige vergelykings van die fisiese teorie. Voorstellings (bv. van atome) word gemaak en meetkundige afmetings (daarvan) bereken alleen om na te gaan in hoeverre die verwagtings redelik is en inpas by die fisiese wêreldbeeld.

Schrödinger' ' gaan uit van die standpunt dat 'n beskrywing of voorstelling alleenlik waar kan wees as dit regstreeks met die feite in ooreenstemming is. So kan ons bv. nie regstreeks deur' $n$ eksperiment die ruimtelike vorm van 'n atoom vasstel nie. Alleen op 'n indirekte wyse kan die vorm bereken word. Dan het ons volgens Schrödinger alleen met 'n model van ' $n$ atoom te doen en nie met ' $n$ werklike atoom nie. So ook word die reekse van spektraallyne wat ' $n$ bepaaide element uitstraal, teruggevoer in hulle oorsprong na die atome van die element en verklaar deur die verandering wat in die elektriese samestelling van 'n atoom sou plaasvind. Ook hier moet die elektriese samestelling van 'n atoom as model gesien word om die oorsprong van die spektraallyne te verklaar.

4. Individualiteit van die diskrete deeltjies en die onbepaaldheidsbeginsel:

Democritus en almal wat hom gevolg het tot die einde van die vorige eeu. het atome beskou as identifiseerbare klein harde balletjies met 'n eie individualiteit. Die klassieke Fisika het steeds by teoretiese beskouings van die gedagte uitgegaan dat ons 'n bepaaide massadeeitjie steeds kan bly waarneem en aldus presies kan volg. Daarom sal sy verdere pad presies vooruit bereken kon word as alle faktore, wat hom kan beïnvloed. bekend was.

Volgens die teoretiese ontwikkeling in die huidige Fisika het atomêre deeltjies nie meer 'n eie individualiteit nie. Verskillende deeltjies van dieselfde massa, elektriese lading en in alle ander meetbare eienskappe gelyk, kın nie op atomêre skaal eksperimenteel van mekaar geskei word nie.

Volgens die nuwere Natuurkunde kan 'n massadeeltjie deur waarneming op atomêre skaal nie meer gevolg word sonder dat die waarneming sy beweging versteur nie. Alle bekende eksperimentele metodes, al word dit ook onder die ideaalste gedagte-omstandighede toegepas, sal by waarneming van ' $n$ atomêre deeltjie sy beweging versteur. Omdat dic mate van versteuring wat ' $n$ fisiese meting veroorsaak, nie presies bepaalbaar is nie, het 'n noukeurige vooruitberekende weg vir' $n$ bepaalde deeltjie geen sin nie, al sou dit moontlik wees, want sodra ons die beweging langs die teore-

(1) E. Schrödinger, Science and Humanism (Cambridge Univ. Press, 1952), bl. 22. 
ties-berekende weg eksperimenteel wil verifieer, sal die deeltjie se weg nadat die meting verrig is, onbepaald wees. Dit is dan ook die geval met die bane van deeltjies wat in 'n wolkkamer of fotografiese emulsie sigbaar gemaak word. In albei apparate beweeg die deeltjies tussen die atome van die medium deur. Hierdie atome waarlangs die deeltjie beweeg bepaal uiteindelik die weg van die deeltjie en die se relatiewe posisies is onvoorspelbaar. Wel kan op 'n waarskynlikheidsbasis die moontlike weë, wat gevolg kan word, bereken word.

Waarnemings op 'n atomêre skaal moet geskied met meet-apparatuur met materiële struktuur van dieselfde grofheid as die atoom self, of anders met snelbewegende deeltjies of energiestrale, waarvan die energie die waar te neme proses of beweging versteur. Wil ons bv. deur waarneming nagaan presies hoe die elektrone in 'n atoom beweeg, sal ons daardie beweging so versteur dat ons waarnemings nie voltrek kan word nie.

Deur die diskreetheid van die bekende meetmetodes van kernfisiese prosesse bly ons altyd 'n onsekerheid in ons resultate behou. Die grootte van die onsekerheid in ons metings hang saam met die werkingskonstante, $h$, van Planck, wat 'n fundamentele natuurkonstante is, en saamhang met die kwantisering van die energie van ligstrale. Heisenberg het die samehang tussen die onbepaaldhede van verskillende fisiese groothede wiskundig geformuleer. Hierdie formulering word dan ook die onbepaaldheidsbeginsel van Heisenberg genoem.

\section{Statistiese aard van die nuwere Fisika:}

In die beskrywing van atomêre prosesse moes die klassieke meganika plek maak vir die golf- en kwantummeganika van Schrödinger en Heisenberg. Die klassieke meganika het atomêre prosesse te presies beskryf om korrelasie met meetresultate moontlik te maak. As gevolg van die diskreetheid van materie en van stralingsenergie word by meting aan atomêre prosesse 'n onbepaaldheid gegee wat tot die gevolg het dat die meetresultate statisties van aard is. Hierby is die teorie aangepas om korrelasie moontlik te maak. Daarom dan ook dat die onbepaaldheidsbeginsel van Heisenberg in die teorie van die golf- en kwantummeganika ingesluit is. Die golfmeganika gee dan ook 'n waarskynlikheidsfunksie wat die kans aandui om 'n bepaalde eksperimentele resultaat te vind of dat 'n proses op ' $n$ bepaalde wyse sal verloop.

Ons het dan hiermee ook 'n bepaalde standpunt ingeneem, nl. dat die statistiese onnoukeurigheidspreiding van die meetresultate van identiese 
metings te wyte is aan die diskreetheid van massa en stralingsenergie, wat die fynste meetinstrumente tot ons beskikking is en waarvan die grootteorde dieselfde is as die voorwerpe wat waargeneem word. Die indeterministiese beskrywing wat die teoretiese Fisika in 'n sekere sin van die natuur gee, wil dus nog nie sê dat die natuur self indeterministies in die wese van die individuele prosesse is nie. Gaan ons daarvan uit dat alles, dus ook die mikrofisiese prosesse, onder die wetsorde van God staan, sal die individuele prosesse 'n vaste wetsorde moet hê.

Die meetproses en die werklikheid wat gemeet word, kan ons nie van mekaar losmaak nie. Hulle moet saam teoreties beskryf word. As die meetproses 'n onbepaaldheid meebring, moet dit ook in die teorie opgeneem word. Die individuele natuurprosesse kan dus nog noukeurig volgens wette verloop. Vir die wysgeer N. Hartman?) o.a. hou die wetmatigheid in die st atistiese verloop van die prosesse noodwendig in dat ook die individuele prosesse noukeurig volgens wette moet verloop.

in Alternatiewe beskouing is moontlik indien die onbepaaldheid in die meetprosesse toegeskryf word aan ' $n$ onbepaaldheid in die individuele prosesse self. Dan word die onderskeiding tussen meetproses en werklikheid nie in ag geneem nie en die meetproses en werklikheid aan mekaar gelyk gestel. Die individuele prosesse word dan self indeterministies.

In die begin van hierdie dekade het verskillende natuurkundiges3) nog pogings aangewend om terug te keer tot die objektiewe realiteitsbeskouing van die klassieke Fisika. Nie een van die pogings om die golfmeganika tot 'n teorie volgens klassieke riglyne en beginsels om te werk het enige sukses behaal nie. Met hierdie pogings moes telkens essensiële simmetrie-eienskappe van die kwantumteorie opgeoffer word.

Een van die essensiële simmetrie-eienskappe van die kwantumteorie is dat dit vir die teorie om 't ewe is of ons die atomêre deeltjies as massadeeltjies of wel as golwe gaan beskou. Maar wat is nou in werklikheid hierdie deeltjies wat net so wel golwe as massadeeltjies kan wees? Born4) sien die fisiese realiteit van hierdie deeltjies in daardie fisiese eienskappe wat onveranderlik blyk te wees, d.w.s. die eienskappe waarvoor ons altyd weer die-

2) N. Hartman, Philosophie der Natur (Walter de Gruyter \& Co., Berlin, 1950).

3) Sien W. Heisenberg. The development of the interpretation of the Quantum Theory, onder redaksie van W. Pauli, Niels Bohr and the development of Physics (Pergamon Press, London, 1955).

4) M. Born, Natural Philosophy of Cause and Change (Oxford 1948), bl. 101 e.v. 
selfde getalswaardes by metinge kry, bv. die lading en die massa van 'n elektron. Volgens hierdie uitgangspunt moet iets soos die elektron werklik bestaan, en wat ons daarvan seker weet is die grootte van sy lading, massa en ander fisiese groothede. Verdere informasie omtrent die wese van die elektron as die fisiese gee die eksperiment nie.

\section{Massadeeltijies en antideeltjies:}

Die lys van saamgestelde en elementêre massadeeltjies word nog steeds jaarliks aangevul. Die massawaardes van hierdie deeltjies lê tussen dié van die elektron, die ligste gelaaide deeltjie bekend, en dié van waterstof, die ligste atoom, en ook tussen die massawaardes van waterstof, die ligste atoom, en ook tussen die massawaardes van waterstof, deuterium, helium en net swaarder as helium. Die meeste van hierdie intermediêre massadeeltjies is radioaktief-onbestendig. Sommige reageer ook baie sterk met materie.

Verlede jaar is die bestaan van twee nuwe massadeeltjies aangetoon, nl. 'n negatiewe of antiproton en 'n antineutrino. Die bestaan van hierdie twee deeltjies is op grond van fisies-wiskundige beskouinge al reeds baie jare gelede voorspel, ook hulle eienskappe en reageervermoë met materie.

Die antiproton het volgens die meetresultate, in ooreenstemming met die teorie, dieselfde massa as die gewone proton, die waterstofkern. Waar die proton elektries positief is, is die antiproton elektries negatief. Verder het die antiproton volgens die teorie, 'n negatiewe massa, waar die massa van die proton positief is, en in getalwaarde gelyk is aan die massa van die antiproton. As 'n proton en ' $n$ antiproton mekaar dus ontmoet, sal die positiewe massa van die proton geheel en al in die negatiewe massa van die antiproton moet opgaan. en albei massadeeltjies sal dan verdwyn. Hierby sal dan volgens die beginsel van behoud van massa en energie, energie moet vrykom gelyk aan die totale massaenergie van die twee deeltjies. Dit is dan ook wat inderdaad eksperimenteel gevind is. 'n Antiproton blyk in materie. wat o.a. uit protone saamgestel is, alleen 'n baie kort tydjie te bestaan. want al gou word 'n proton ontmoet waarmee dit kan annihileer.

Presies dieselfde is die geval met die positron, wat 'n anti-elektron is en 'n positiewe lading en ' $n$ negatiewe massawaarde het. Die positron is voor die dertiger jare teoreties voorspel en daarna in 1934 eksperimenteel ontdek. Die antineutrino is nie in 'n vernietigingsproses ontdek nie, maar uitgeken op grond van die waarskynlikheid om 'n omgekeerde beta-proses te laat plaasvind. 
Uit ons makroskopiese ervaring ken ons alleen positiewe massawaardes. Alle materie wat ons uit hierdie ervaring ken trek mekaar aan volgens die swaartekragswet van Newton. Vandaar dan ook dat alle materie wat ons ken gewig besit wat ' $n$ gevolg is van die aantrekkingskrag van die aarde op alle massas volgens die swartekragswet. Op grond van hierdie wet sou dus negatiewe en positiewe massas mekaar moet afstoot. Dit is egter nie hierdie afstoting wat eksperimenteel waargeneem is tussen massadeeltjies om daaruit op die negatiewe massa van die antideeltjies te besluit nie. Die enigste grond waarop die massas van die antideeltjies as negatief aangeneem word is die interpretasie van 'n fisies-wiskundige teorie, wat deur Dirac ontwikkel is. Dirac het nl. die wortel getrek van die verband tussen die totale energie, $\mathrm{E}$, van 'n deeltjie, sy massa, $\mathrm{m}$, en sy momentum, $\mathrm{p}$, wat volg uit die relatiwiteitsteorie van Einstein:

$$
E^{2}=p^{2} c^{2}+m^{2} c^{4}, c=\text { ligsnelheid. }
$$

Omdat die massa in hierdie vergelyking in die kwadraat staan kan dit positief of negatief wees. Omdat daar wiskundig geen rede was om negatiewe massawaardes buite rekening te laat nie, het Dirac tot die gevolgtrekking gekom dat indien sy teorie 'n natuurgetroue beskrywing vir deeltjies met positiewe massawaardes is, dit ook ewe goed deeltjies met negatiewe massawaardes sal moet beskryf. Aldus het hy kon voorspel wat die eienskappe van hierdie antideeltjies is, wat dan ook in die genoemde gevalle eksperimenteel bevestig is.

Hierdie verskynsels laat die vraag wat materie nou eintlik is, weer sterk op die voorgrond tree. Materie blyk diskreet te wees. Materie kan hom egter ook van ons fisiese waarnemingsvermoë onttrek wanneer' $n$ deeltjieantideeltjiepaar mekaar annihileer, en al wat ons oorhou is energie. Die ongekeerde vind ewe goed plaas. Energie kan naamlik verdwyn en 'n deeltjie-antideeltjiepaar kom tevoorskyn, m.a.w., energie is volkome gematerialiseer.

Wanneer nou 'n massadeeltjie by so 'n annihilasie-proses verdwyn, kan dit wees dat massa vernietig word en alleen energie oorbly volgens die wet van behoud van massa en energie, maar dit is ook moontlik dat die massadeeltjie hom alleen aan ons waarnemingsvermoë onttrek sonder om vernietig te word. By die proses van onttrekking sal dan die ekwivalente hoeveelheid energie, soos waargeneem, moet vrykom. Die teorie van Dirac huldig die laasgenoemde beskouing, waaruit die afleiding volg dat die totale aantal elementêre massadeeltjies in die heelal konstant is omdat hulle uiteindelik dan nóg vernietig nóg geskep kan word. By die interpretasie van Dirac se teorie moet ons veronderstel dat daar nog 'n ekstra fisiese dimensie 
moet bestaan, waaruit materie tevoorskyn kan tree of in kan verdwyn. Hierdie onsigbare fisiese dimensie veronderstel 'n negatiewe energietoestand, wat met materiedeeltjies met positiewe massawaardes gevul is. Word een van hierdie deeltjies uit hierdie negatiewe energietoestand verwyder, bly ' $n$ onbesette negatiewe energietoestand oor wat hom presies soos die antideeltjies gedra en dieselfde fisiese eienskappe as die antideeltjies het. Van hierdie nuwe fisiese dimensie is onlangs gebruik gemaak om sekere klein afwykings in die energietoestande van die waterstofatoom te verklaar. Die negatiewe elektron van die waterstofatoom word veronderstel om die gelaaide deeltjies in die onsigbare negatiewe energietoestand elektries te polariseer, waardeur sy energiebinding effens gewysig word. Daarmee is die eksperimentele resultate weer in ooreenstemming met die teorie gebring. Vir baie teoretiese fisici bevredig hierdie nuwe teoretiese ontwikkeling, wat weer 'n soort eter invoer, geensins nie vanweë die spekulatiewe element van die interpretasie van die teorie. Op die oomblik is daar egter nog geen alternatiewe teoretiese beskouing nie.

In wat hierbo aangehaal is moet ons altyd in gedagte hou dat ons aan die een kant die realiteit van die fisiese verskynsels het waarin die verskillende massadeeltjies optree en aan die ander kant 'n fisiese teorie, waarvan die interpretasie in wisselwerking met die natuurverskynsels ' $n$ sekere beeld van die prosesse laat vorm.

Elke nuwe ontdekking wat die mens maak in sy ondersoek van die natuur kom as ' $n$ verrassing en getuig van die wonderwerk van die skepping van God. Die ondersoek van die natuur deur die mens is egter net ten dele, omdat die volle omvang van die skepping vir die mens in sy tydelike bedeling verborge sal bly vanweë die sondeval. Nogtans is aan die mens die bevel gegee om alles te onderwerp en daaroor te heers. Dit is 'n opdrag wat nie versaak mag word nie, maar met alle mag na sy beste verwoë tot eer van God uitgevoer moet word.

Graag wil ek van hierdie geleentheid gebruik maak om my dank uit te spreek teenoor die hooggeagte lede van die Raad en Senaat van ons Inrigting vir die vertroue in my gestel om my in hierdie verantwoordelike betrekking aan te stel. Vir die beoefening van die Natuurkunde in die lig van die beginsel van ons Universiteit kan u verseker wees van my beste toewyding.

Aan u, hooggeleerde Rektor. Here Professore en namec an Hara I al 
van u mog ondervind het gedurende die jare wat ek as dosent en vroeêr as student aan ons Inrigting werksaam was.

Graag wil ek in besonder my dank en waardering betuig aan u, hooggeleerde prof. D. J. van Rooy, en in hul afwesigheid aan my leermeesters. die hooggeleerde here professore G. J. Sizoo, R. W. James en dr. S. J. du Toit, vir die leiding en vorming wat ek as student en later as dosent van $u$ mog ontvang het en waarop ek kon voortbou in my verdese studies en arbiedsterrein.

Aan almal in die Natuur- en Wiskunde-departemente ' $n$ besondere woord van waardering vir ons hartlike samewerking en onderlinge vertroue in ons sake van gemeenskaplike belang. Mag hierdie samewerking en vertroue steeds ons onderlinge verhoudings kenmerk.

Geagte Dames en Here Studente,

Geagte Dames en Here, ek dank u vir u welwillende gehoor.

\section{Algemene Verwysings:}

Du Toit, S. J., Calvinisme en Natuurkunde, Koers DI. XII (Okt., 1944), bl. 55.61.

Jonker, C. C., Werklikheid, Waarnening en Theorie in de Natuurkunde (J. H. Kok, Kampen, 1951).

Planck, M., Vortrage und Erinnerungen (Hirzel Verlag, Stuttgart, 1949).

Sizoo, G. J., Wat is Natuurkunde? (Interfacultaire Colleges, Vrije Universiteit, 19491950).

Sizoo, G. J.. De Herziening van het Physische Causaliteitsbeginsel (J. H. Kok, Kampen, 1952).

Sizoo, G. J., Physica en Werklikheid (G. F. Hummulen, Assen, 1940).

Stoker. H. G., Beginsel- en Metodeleer, deel A (P.U. vir C.H.O., 1956).

Van Rooy, D. J., Bzginsel- en Mztodzleer, dezl B (P.U. vir C.H.O.. 1956).

Van Rooy, D. J., Beskrywing en Verklaring in die Natuurwetenskap, Koers, DI. XXIII (Febr. 1956). bl. 200-9. 